Original Artic

\title{
Study on Clinicopathologic Correlation of Malignant Tumors of Urinary Bladder
}

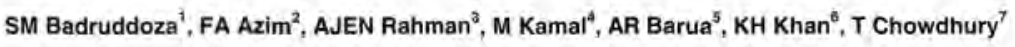

\section{Abstract}

A total of 57 cases clinically suspicious to be urinary bladder malignancies were studied for clinico-histopathological correlations. Patients had different age ranges, sexes, occupations and habit of smoking but all of them presented with painless gross or microscopic haematuria. Histopathological examinations revealed all as malignant tumors of different types and grades. Gross male smokers preponderance and significant proportion of cases from age range 50 to 80 years were noted. So in a proper clinical setting, every haematuria case should be evaluated specially for bladder malignancy.

TAJ $2001 ; 14(2): 81-84$

\section{Introduction}

Carcinoma of the urinary bladder affects men more often than women at a ratio of $3: 1$ to 4:1. This difference is probably related to differences in smoking habits and occupational exposure in two sexes. ${ }^{1}$ Most cases present in patients over the age of 50 years, but they can also occur in younger adults and children. ${ }^{2}$

Haematuria is the most common symptom of transitional cell carcinoma, followed by symptoms related to associated urinary tract infection. Dysuria is more often seen with highgrade tumors perhaps as a result of involvement of the bladder wall. ${ }^{2}$ In the Department of Urology. Bangabandhu Sheikh Mujib Medical University
(BSMMU), Dhaka, in a study of 202 patients presenting with haematuria, malignant lesions were diagnosed in $97(48.01 \%)$ patients. The commonest malignant lesion $(32.17 \%)$. was transitional cell carcinoma $(\mathrm{TCC})^{3}$

This study is designed to correlate clinical findings regarding age, sex, occupation, smoking habit and clinical presentations among patients having malignant tumors of the urinary bladder.

\section{Materials and Methods}

The study was carried out in the Department of Pathology, BSMMU Dhaka, during the period from January io December 1997.

\footnotetext{
' Assistant Prolessor, Deparmment of Pathology, Ra shahi Medical College, Rajshahi-6000, Banglacesh

2 Former Prolessor. Department of Pathology, BSMMU, Dhaka-1205, Bangladesh.

I Prolessor, Department of Paihology, BSMMU, Dhaka-1205, Bengladesh.

${ }_{4}$ Associate Prolessor. Department of Pathology, BSMMU, Dhaka-1205, Bancladesh

${ }^{5}$ Associate Prolessor, Department of Pathology, BSMMU, Dhaka-1205, Bangladesh

I Assistant Prolessor, Deparment of Pathology, BSMMU, Dhaka-1205, Bangladesh.

'Assstant Prolessor, Department of Patnology, BSMMU, Ohaka-1205, Bangladesh.
} 
A total of fifty-seven patients clinically suspicious of having urinary bladder malignancy or histologically confirmed patients, admitted in the Urology Department of BSMMU, DMCH and private clinics were included in this study, Clinical information were obtained with particular reference to the age, sex, profession, smoking habit, history of haematuria, mode of onset of symptom and from detailed clinical examination with emphasis on the urinary bladder.

All biopsy specimens either cystoscopic biopsy or cystectomy specimens were collected on $10 \%$ formalin and after careful gross examination, the specimens were subjected to routine histological processing and routine haematoxylin and eosin stained slides were critically examined to evaluate histological features.

\section{Results}

The purpose of the present study is to see the correlation of clinical findings and histologic diagnosis of urinary bladder malignancy. A total of 57 cases were included in this study.Age of the patients ranged from $30-90$ years (Table-I). The mean is 60 years approximately. Most of the cases of carcinoma of the urinary bladder present in patients over the age of 50 years. It was observed that $33.34 \%$ of the cases were found in $61-70$ years age group and about $63 \%$ of the cases in $50-80$ years age group respectively.

Table I: Age distribution ( $\mathrm{n}=57$ )

\begin{tabular}{ccc}
\hline Age groups in years & No. of cases & Percentage \\
\hline $30-40$ & 10 & $17.54 \%$ \\
$41-50$ & 09 & $15.79 \%$ \\
$51-60$ & 10 & $17.54 \%$ \\
$61-70$ & 19 & $33.34 \%$ \\
$71-80$ & 07 & $12.29 \%$ \\
$81-90$ & 02 & $3.50 \%$ \\
Total & 57 & $100 \%$ \\
\hline
\end{tabular}

There were $50(87.71 \%)$ male and 07 (12.29\%) fernale patients (Table-II). The male to female ratio was 7:1 (approximately).
Table II: Sex distribution $(n=57)$

\begin{tabular}{lcc}
\hline Sexes & No. of cases & Percentage \\
\hline Male & 50 & $87.71 \%$ \\
Female & 07 & $12.29 \%$ \\
Total & 57 & $100 \%$ \\
\hline
\end{tabular}

Out of total 57 cases, $20(35.07 \%)$ were cultivators, $15(26.32 \%)$ were service holder, another $15(26.32 \%)$ were businessman and 07 $(12.29 \%)$ were housewives. No industrial worker or persons working in the chemical industries were included in this study population (Table-III).

Table III: Occupation $(n=57$ )

\begin{tabular}{lcc}
\hline Decupation & No. of cases & Percentage \\
\hline Cultivator & 20 & $35.07 \%$ \\
Serviec & 15 & $26.32 \%$ \\
Business & 15 & $26.32 \%$ \\
Housewife & 97 & $12.29 \%$ \\
Total & 57 & $100 \%$ \\
\hline
\end{tabular}

There were $36(63.16 \%)$ smokers and $21(36.84 \%)$ non-smokers (Table-IV).

Table IV: History of smoking $(n=57$ )

\begin{tabular}{lcc}
\hline History & No. of cases & Percentage \\
\hline Smoker & 36 & $63.16 \%$ \\
Nori-smoker & 21 & $36.84 \%$ \\
Total & 57 & $100 \%$ \\
\hline
\end{tabular}

The commonest symptom (Table-V) was painless gross or microscopic haematuria. $100 \%$ of the cases presented with this symptom. This was the dominant and some times the only clinical manifestation. The other common features were dysuria $(49.12 \%)$, burning $(36.84 \%)$, frequency or urgency (31.57\%), nocturia (21.06\%), suprapubic pain $(12.29 \%)$, incomplete voiding $(10.52 \%)$, incontinence $(5.27 \%)$ and hesitancy $(1.76 \%)$. Fever and general weakness was also common associated manifestations occurring in $42.10 \%$ and $3.77 \%$ patients respectively. These are probably due to secondary infections of the urinary tract, old age and repeated haematuria. 
Table V: Frequency of symptoms $(n=57$ )

\begin{tabular}{lcc}
\hline Symptoms & No. of Patients & Percentage \\
\hline Pairless haematuria & 57 & $100 \%$ \\
Nocturia & 12 & $21.06 \%$ \\
Frequency/Lrgency & 18 & $31.57 \%$ \\
Dysural & 28 & $49.12 \%$ \\
Suprupubic pain & 07 & $12.29 \%$ \\
Burning & 21 & $36.84 \%$ \\
Hesitancy & 01 & $1.76 \%$ \\
Incomplete voiding & 06 & $10.52 \%$ \\
Incontinence & 03 & $5.27 \%$ \\
Fever & 24 & $42.10 \%$ \\
General weakness & 05 & $3.77 \%$ \\
\hline
\end{tabular}

Table VI shows the histologic diagnoses of 57 eases. There were $42(73.68 \%)$ invasive carcinomas of all grades and types, 14 (24.56\%) non-invasive papillary tumors and $01(1,76 \%)$ carcinoma in-situ.

TableVI: Histopathological diagnosis ( $n=57$ )

\begin{tabular}{lcc}
\hline Histulogic Diagnosis & No. of cases & Percentage \\
\hline Non-invasive Papillary murner & {$[4$} & $24.56 \%$ \\
Non-papillary carcinoma in situ & 01 & $1,76 \%$ \\
Invasive carcinoma & 42 & $73.68 \%$ \\
(all grades/types) & & \\
Total & 57 & $100 \%$ \\
\hline
\end{tabular}

\section{Discussion}

The masculine prevalence was confirmed which included 50 men and 7 women in this study of malignant tumors of urinary bladder. The age range was 30-90 years with an average of 60 years (approximately). Male to female ratio was 7:1, Histologic diagnosis was made in symptomatic patients and $100 \%$ of the patients presented with gross or microscopic painless haematuria.

Regarding occupation about $35 \%$ were cultivators followed by $26 \%$ businessman and service holder each. In $63 \%$ of cases, there was a positive history of smoking.

In a study of 129 patients, the majority of the patients $(80 \%)$ were between $60-75$ years ${ }^{4}$. Men predominated as $3: 1$. in another study $y^{5}$. In another study of 181 patients, age ranged from 25 93 years (mean age 63yrs) and male to female ratio was 2.3:1. ${ }^{6}$ All these findings are in accordance of our findings.
The age and sex incidence in this series corresponded to what others have reported for patients with malignant lesions of urinary bladder. The male predominance of tumots over female in our country may be partly due to the differences in smoking habit and occupational exposure in two sexes.

Regarding occupation most of the patients were cultivators. In developed nations, the disease is prevalent among industrial workers exposed to chemical carcinogens. In a developing country like ours, though no specific cause is yei identified, environmental factors like the use of pesticides may be taken as a possible factor related to bladder carcinogenesis. The causes of bladder cancer, particularly in a developing country should be sought for, as it is seen from the study that the disease is more prevalent among cultivators and smokers.

Cigarette smoking is clearly the most important influence, increasing the risk 3.7 folds and it has been estimated that $50-80 \%$ of bladder cancers among men can be attributed to the habit of cigarette smoking. ${ }^{4,7}$. In this study there were $36(64 \%)$ smokers which is in concordance with other studies.

In a study, gross or microscopic haematuria was the most consistent presenting feature noted in $82-94 \%$ of case. ${ }^{7}$ So one must evaluate cases of haematuria with great caution.

\section{Conclusion}

Patients having malignant lesions in the urinary tract particularly urinary bladder usually presented with haematuria. So all patients presenting with urinary symptoms particularly haematuria, should be evaluated thoroughly, In selected cases presenting with haematuria clinically suspicious to be malignant bladder tumors, before going to perform any invasive procedures like cystoscopy, urine cytology can be done. It is advocated specially for people in the developing countries because it is very cost effective, non-invasive simple tool with very encouraging positive results. 


\section{Bibliography}

1. Reuter VE. The Lower Urinary Tract. In: Sternberg SS. Ed: Diagnostic Surgical Pathology New York. Raven press. 1989;1355-1392.

2. Rosai J. In Ackeman's Surgical Pathology. $7^{\text {th }}$ edition. St. Louis, C.V. Mosby, 1989; 898-922.

3. Kibria SAMG, Kabir J, Hasan S. Evaluation of 202 patients with haematuria. Journal of Institute of Postgraduate Medicine and Research 1996 :2: 6-8.
4. Cotran RS, Kumar V, Robbins SL. Pathologic Basis of Disease. $5^{\text {th }}$ Edition. Philadelphia. W.B. Saunders company. 1994; 991-1005.

5. Holmquist ND. Detection of urinary tract cancer in urinalysis specimens in an out patient population. AJCP 1988; 89: 499-504.

6. Giella JG, Aing K, Olsoon CA, Karp FS, Benson MC. The predictive value of flow cytometry and urinary cytology in the follow up of patients with TCC of the bladder. Urol 1992; 148: 293-296.

7 Geisse LJ, Tweeddate DN. Pre-clinical cytological diagnosis of bladder cancer. Urol $1974 ; 120: 51-56$.

All correspondence to: Dr. Shah Md. Badruddoza Assistanl Prafessor Department of Pathology Rajshahi Medical College Rajshahi-6000, Bangladesh 